\title{
ANTIAUTOBIOGRAFIA E EXTINÇÃO: ANÁLISE DE ALGUNS ASPECTOS DA ESTRUTURA NARRATIVA DE AUSLÖSCHUNG. EIN ZERFALL
}

\author{
Patricia Miranda Dávalos*
}

\begin{abstract}
RESUMO: “Auslöschung. Ein Zerfall” de Thomas Bernhard é o único romance do autor a simular claramente o gênero autobiográfico, no qual, segundo fórmula de Genette, autor=narrador=personagem. Tal construção traz a possibilidade de uma narrativa com unidade e coerência entre personagem e estilo, como o texto que segue procura demonstrar: ao colocar Murau como autor da obra, Bernhard obteve sucesso em construir um relato no qual a visão do personagem está implícita a todo instante, obtendo um resultado altamente subjetivo e tendencioso. Ao mesmo tempo tal opção traz um a dificuldade: apresentar a morte do narrador-protagonista - uma necessidade do romance, como será apresentado no artigo - num relato escrito em primeira pessoa.
\end{abstract}

PALAVRAS-CHAVE: Thomas Bernhard - Estrutura Narrativa - Autobiografia Ficcional

\begin{abstract}
Thomas Bernhard's "Auslöschung. Ein Zerfall” is his only novel that imitates clearly the autobiographical genre, which, according to Genette, presents the equation Author $=$ Narrator $=$ Character. This construction makes possible a narrative with unity and coherence between character and style, which the following article intends to demonstrate: putting Murau as the text's author, Bernhard is successful in building a narrative in which the character's point of view is constantly present, so the result is highly subjective and tendentious. At the same time this choice brings a challenge: to present the narrator-protagonist's death - a necessity of the novel, that will be discussed in this article - in a narrative written in the first person.
\end{abstract}

KEYWORDS: Thomas Bernhard - Narrative Structure - Fictive Autobiography

\section{INTRODUÇÃO}

Em 1986 é publicado Auslöschung. Ein Zerfall (na tradução brasileira Extinção. Uma Derocada), último romance de Thomas Bernhard. Durante a sua leitura, o leitor logo percebe que Auslöschung também pretende ser o título da "antiautobiografia" escrita pelo narrador protagonista Franz-Josef Murau, de modo que, à exceção de duas inserções na primeira e última frase do texto, que servem de moldura ao mesmo, o livro apresenta-se como um escrito da personagem.

A ação é resumível em poucas linhas: na primeira parte do livro, "Das Telegramm", Murau, um intelectual austríaco, a fim de afastar-se da família e pátria, decide exilar-se em Roma, onde leciona ao jovem Gambetti e onde recebe, repentinamente, um telegrama comunicando a morte dos pais e irmão. Na segunda parte, "Das Testament", o leitor vê o retorno de Mura à Áustria, mais especificamente a Wolfsegg, para participar do enterro dos familiares.

\footnotetext{
Aluna do programa de mestrado em Literatura Alemã da Universidade de São Paulo. E-mail: patricia.davalos@zipmail.com.br
} 
O objetivo do texto que se segue é apresentar uma breve análise do romance concentrando-se na figura do narrador, instância fundamental na construção dessa obra, a qual é concebida como uma autobiografia, de forma a trazer consigo alguns pressupostos - por exemplo, o do relato homodiegético -, que determinam seu estilo, estrutura, seleção de episódios narrados, etc. Além disso, como já mencionado, essa autobiografia ficcional é emoldurada por inserções em seu início e fim, configurando uma instância narrativa anônima e estranha ao texto, a qual deve ser considerada pelo leitor e cuja função em relação ao resto do romance será tema da segunda parte dessa análise.

A fim de melhor determinar a função do narrador do romance, a análise tomará como base metodológica os textos de Stanzel (1965) e Genette (1983), ambos relevantes para a crítica literária e que apresentam vários pontos de contato e complementares, recorrendo-se aqui a um ou outro conforme seja a nomenclatura mais específica em relação ao caso comentado - as semelhanças e diferenças entre os dois autores, quanto a suas análises de estruturas narrativas, foram apresentadas pelo próprio Genette em seu Nouveau Discours du Récit, no qual o autor chega a ampliar seu quadro do narrador, incluindo alguns dos conceitos apresentados por Stanzel ${ }^{1}$.

\section{CONSTRUÇÃO DE UMA AUTOBIOGRAFIA FICCIONAL}

\section{Imitação do gênero autobiográfico: unidade e tensão}

É lugar comum na retórica antiga, como salienta Stanzel no início de seu Typische Formen des Romans, que "verschiedene Redestile oder Erzählweisen verschiedene Wirkungen auf den Zuhörer oder Leser ausüben"2 (1965, p.3). Tal fato valeria também para o romance, de modo que ao analisar a estrutura narrativa de Auslöschung, objetiva-se igualmente observar os efeitos provocados por ela e suas implicações para o romance como um todo.

A primeira característica, a qual, aliás, é fundamental para condicionar a leitura de Auslöschung é o fato do mesmo apresentar-se como uma autobiografia. Segundo Lejeune (in NIGGL, 1989, 255s.), determinar se um texto é ficcional ou factual dependeria principalmente de elementos paratextuais, como uma nota na contracapa ou uma designação genérica após o título. Fora isso, a identidade entre autor e personagem ajudariam a identificar em um texto o pacto estabelecido entre leitor e autor como autobiográfico.

Genette amplia a equação que caracteriza a narração autobiográfica para a seguinte: se Autor $=$ Narrador e Narrador $=$ Personagem, logo Autor $=$ Personagem, ou

\footnotetext{
${ }^{1}$ cf. GENETTE, 1983, 77ss. No capítulo "Situations Narratives" o autor apresenta considerações sobre a tipologia de Stanzel, uma vez que ambos haviam sido anteriormente comparados por Dorrit Cohn, a qual mostrara, em artigo citado por Genette, as principais diferenças entre as abordagens dos autores em Discours du récit e em Theorie des Erzählens, respectivamente. Tais diferenças também são citadas por Genette e igualmente podem ser conferidas no capítulo indicado.

2 "diferentes estilos de discurso, bem como diferentes modos de narrar, provocam diferentes efeitos no ouvinte ou leitor". Para trechos de Auslöschung apresenta-se no corpo do texto a tradução publicada pela Companhia das Letras (cf. bibliografia), seguida do original em nota - o inverso, citação do original com a tradução em nota, só é feito caso necessário para melhor exemplificar o caso discutido. A indicação de páginas ao longo do texto, caso não exista ressalva, também refere-se à tradução. Para citações de textos não traduzidos disponho minha versão em português em nota de rodapé.
} 
seja, $\mathrm{A}=\mathrm{N}=\mathrm{P}$ (GENETTE, 1991, p.84). Uma análise do texto de Murau, desconsiderando-se sua moldura, o coloca na categoria de uma autobiografia, que é justamente o que pretende ser - uma autobiografia fictícia, naturalmente, pois seu autor é fictício. Dentro do universo estabelecido por Bernhard nesse romance, o pacto estabelecido por Murau com seu leitor é autobiográfico ${ }^{3}$, embora, curiosamente, Murau pareça ignorar seu leitor: o diálogo de seu texto parece ser sempre consigo próprio, praticamente não é tematizada a recepção do texto por um futuro leitor.

A unidade narrador-personagem-autor (fictício) tem como conseqüência para o relato exposto uma coerência entre forma e conteúdo narrado, de modo que outra construção narrativa não teria tal unidade, não colocaria o leitor tão próximo do universo trágico-cômico de Murau, como ele se refere a sua experiência: "uma tragédia que ao mesmo tempo é uma perfeita e pérfida comédia." (p.148).

Voltando a Stanzel, ele faz algumas observações pertinentes quanto ao que chama "Ich-Erzählsituation" (narração em primeira pessoa), a qual corresponde à situação narrativa do texto em questão, merecendo por isso ser discutida aqui. No caso da ficção homodiegética, Stanzel diferencia duas situações principais: na primeira o narrador-personagem não está no centro da ação, mas à margem dela, funcionando como um observador/testemunha, de modo que a cena é apresentada ao leitor sob uma perspectiva determinada pela personalidade ou intenção do personagem. A segunda situação narrativa homodiegética seria a exposta nos "quasi-autobiographische IchRomane" (ibid., p.31), nos quais o eu-narrador está no centro da ação e o leitor verificaria uma tensão entre o eu que vive a experiência e o eu que a rememora, tensão criada pela distância temporal entre os dois momentos e evidenciada no julgamento de quem mudou sua ideologia ou na nostalgia sentida pelo passado irrecuperável.

Auslöschung, uma pseudo-autobiografia - segundo o pacto que é apresentado ao leitor ao longo do texto e que é tornado explícito no fim do mesmo -, pertence claramente ao segundo tipo: a proposta do personagem (e cumprida por esse) é escrever sua "antiautobiografia", na qual vai falar de todos os complexos ligados à sua origem e formação, temática central proposta para seu escrito, e que por ter como objetivo principal extinguir o rememorado é chamado "antiautobiografia", em oposição à autobiografia usual, a qual visaria à conservação por meio da escrita do passado narrado.

A tensão entre o eu do presente e o eu do passado é verificável nos dois sentidos descritos por Stanzel: em algumas passagens do livro vê-se um Murau que analisa seu comportamento da juventude, quando ainda tentava aproximar-se da família, o que, como adulto, percebe ser impossível. Em outros trechos apresenta-se um personagem a rememorar nostalgicamente alguns episódios da infância, como os momentos vividos na Kindervilla - a nostalgia é tal que pensa em reformá-la, a fim de recuperar um momento idílico de seu passado. O projeto é abandonado diante da constatação de ser impossível recuperar tal tempo.

A escrita autobiográfica, contudo, traz outro tipo de tensão: a existente entre escritor e sua matéria, a qual deve ser narrada com a maior exatidão possível, de forma fiel, mas que só pode ser descrita de forma parcial e subjetiva: "Quero ao menos fazer a

\footnotetext{
${ }^{3}$ Quando se diz que Murau estabelece um pacto autobiográfico com seu leitor é preciso uma ressalva: durante todo o romance, Auslöschung aparece como um projeto a ser realizado futuramente, e apenas com a leitura das últimas frases o leitor descobre ser o relato na verdade a realização da autobiografia, de forma que o pacto autobiográfico torna-se realmente explícito somente ao fim da leitura. Por outro lado, o pacto é antecipado ao leitor já nas primeiras linhas do texto, pela inserção anônima "schreibt Murau, Franz-Josef", a qual indicaria a validade da equação $\mathrm{A}=\mathrm{N}=\mathrm{P}$, e o fato de tratar-se de um texto escrito.
} 
tentativa, dissera a Gambetti, de descrever Wolfsegg como eu a vejo, pois cada qual só pode descrever o que ele vê, como lhe parece, não de outro modo" (p.146) ${ }^{4}$. Essa ressalva impede uma argumentação contra a fidelidade de Murau ao exposto, pois ele só narra o que vê e como vê, ou seja, tudo de um ponto de vista subjetivo - todo o modo como o texto é estruturado contribui para a obtenção de um escrito altamente subjetivo.

A tensão entre o eu do passado e do presente, de qualquer forma, é muito menor que a do eu e de suas origens, das quais busca diferenciação e afastamento - idéia que parece acompanhá-lo ao longo de toda vida. Esta é outra característica do romance pseudo-autobiográfico: "Im Ich-Roman versucht sich ein Mensch selbst zu begreifen, sich zu definieren, von seiner Umwelt abzugrenzen" (ibid., p.36) ${ }^{5}$. Essa busca de definição em oposição ao outro e ao seu meio é constante no relato de Murau: as descrições de Wolfsegg, dos austríacos, vão além do intuito de definir uma época e visam também se definir pela caracterização do outro - definindo a Wolfsegg que todos trazem consigo, pela qual se está impregnado o tempo todo, de forma que falar de Wolfsegg é falar de si. Tal caracterização de si próprio normalmente ocorre por oposição ao outro apresentado (pai, mãe, irmãos, etc), por vezes identificação (tio Georg). No entanto a leitura evidencia que a diferenciação almejada entre eu/mundo não é empresa bem sucedida por Murau, trata-se de algo fora de seu alcance, o que desemboca no trágico de seu relato, como será esclarecido na segunda metade deste texto.

Voltando às duas possibilidades da "Ich-Erzählsituation" retratadas por Stanzel, resta comentar o primeiro caso apresentado, no qual o narrador homodiegético está à margem da ação. Embora tal narrador seja homodiegético, ele pode simular uma situação extradiegética, aproximando-se do narrador observador chamado por Stanzel de "auktoriale Erzählsituation", como outros narradores de Bernhard fazem, principalmente o de Holzfällen, mas também em Der Untergeher e Alte Meister: trata-se sempre de um narrador homodiegético, o qual toma parte na ação, mas que voluntariamente prefere excluir-se, não compactuar com as outras personagens, colocando-se como observador crítico da matéria narrada - o leitor pode chegar mesmo a esquecer-se de que os narradores também são personagens, tal é o distanciamento obtido. Em tais casos, contudo, não se pode falar de uma focalização zero, como seria esperado de um narrador autorial, a focalização continua sendo interna, no caso do narrador personagem, e externa no caso das outras figuras: o narrador só pode dizer o que se passa em seu próprio íntimo, sendo vedado o acesso aos pensamentos dos outros personagens, que são caracterizados por elementos externos, ou seja, por suas falas, ações ou julgamentos do narrador.

Esta parcialidade na apresentação dos personagens é uma característica bastante presente em Auslöschung: ao leitor é difícil julgar, por exemplo, o verdadeiro caráter das irmãs de Murau, das quais temos poucas informações objetivas, pois tudo, mesmo suas ações externas, é filtrado e selecionado por Murau, o qual cria um relato, como o leitor é capaz de reconhecer, bastante parcial e tendencioso. Em Auslöschung, apesar de seu caráter de pseudo-autobiografia, é possível constatar, em conformidade com o acima mencionado, como Murau em diversas oportunidades assume o papel do observador acima da matéria observada, numa posição segura fora da ação, a fim de

\footnotetext{
4 "Ich will wenigstens den Versuch machen, hatte ich zu Gambetti gesagt, Wolfsegg zu beschreiben wie $i c h$ es sehe, denn jeder kann nur beschreiben, was er sieht, wie es ihm erscheint, nicht anders" (1996, p.197)

5 "No romance em primeira pessoa, um indivíduo procura compreender a si mesmo, definir-se, diferenciar-se de seu meio"
} 
avaliar os eventos criticamente e marcar sua posição de quem não compactua com o exposto. Um dos exemplos disso encontra-se na segunda parte do relato, "Das Testament", quando Murau observa, atrás de um muro, os preparativos do enterro e prepara-se, semelhante a um ator, para entrar em cena, analisando para tal o comportamento dos outros personagens e a situação. Durante os preparativos do enterro ele é muitas vezes apenas um expectador do trabalho alheio.

\section{Uso tendencioso do discurso direto e indireto}

O distanciamento em relação à ação obtido por Murau é de tal ordem, que ele por vezes consegue colocar-se mesmo como observador de si próprio - o que pode ser constatado em suas numerosas autocitações -, analisa seu próprio comportamento e chega a auto-interpelar-se pelo uso de "du" (você), estabelecendo um diálogo consigo próprio: "A vida inteira, por mais que tenha tentado, você não conseguiu escapar dessas pessoas(...)" (p.21) "perguntei a mim mesmo" (p.384), etc.

Aliás, nesse escrito de visão tão unilateral e parcial, os diálogos consigo mesmo são mais produtivos e numerosos que os com outros personagens - diálogos estes quase inexistentes. Murau, ao dar voz a outras personagens, especialmente pelo uso do discurso indireto, quase nunca diretamente, o faz de uma maneira muito própria, utilizando citações e trechos desses diálogos em seu favor para fortalecer a idéia que vinha sendo por ele desenvolvida.

Um exemplo interessante do uso de citação do discurso alheio pode ser conferido no seguinte exemplo: Murau comenta as cartas que recebe de pessoas, as quais o criticam por seus artigos publicados em jornais. Tais pessoas o criticam por atacar constantemente a Áustria e seu povo:

Ich $\underline{\text { ziehe }}^{7}$ Österreich andauernd in den Schmutz, sagen diese Leute, die Heimat mache ich auf die unverschämteste Weise herunter, ich unterstellte den Österreichern eine gemeine und niederträchtige katholisch-nationalsozialistische Gesinnung wann und wo ich nur könne, wo es in Wahrheit diese gemeine und niederträchtige katholisch-nationalsozialistische Gesinnung in Österreich gar nicht gäbe, wie

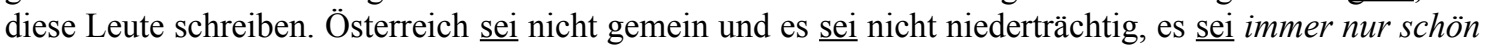
gewesen, schreiben diese Leute, und das österreichische Volk sei ein ehrbares. (19-20) ${ }^{8}$

O texto foi citado no original para destacar o uso especial do tempo verbal empregado pelo autor. Observa-se que Murau começa sua citação usando o Indikativ e termina usando o Konjunktiv, tempo utilizado na língua alemã, entre outras funções, para marcar o discurso indireto e ao mesmo tempo manter uma distância da fala transcrita (cf. a gramática Duden, 2005, p.538). Pela observação do tempo verbal adotado, pode-se supor que Murau não se distancia da afirmação de tais pessoas de que ele criticaria o país e seu povo e os classificaria de nacional-socialistas e católicos, contudo marca distância dos argumentos de que a Áustria e austríacos nada teriam de

\footnotetext{
6 "Diesen Menschen hast du dich zeitlebens, obwohl du immer wieder den Versuch gemacht hast, nicht entziehen können (...)" (p.26)

${ }^{7}$ Grifos meus.

8 "Arrasto a Áustria constantemente na lama, dizem essas pessoas, difamo a pátria da maneira mais despudorada, não perco ocasião de atribuir aos austríacos uma mentalidade abjeta, sórdida e nacionalsocialista na Áustria, como escrevem essas pesoas. A Áustria não era abjeta nem era sórdida, sempre foi somente bela, escrevem essas pessoas, e o povo austríaco era respeitável” (p.16)
} 
baixos ou nacional-socialistas e católicos, mas teriam sido sempre bons - desta última constatação Murau sinaliza distanciamento ainda maior, como indica o uso do itálico. Em alguns casos as formas verbais do presente do indicativo e do Konjunktiv I coincidem, não sendo possível distinguir o uso adotado. No entanto, se houve preferência em manter a ambigüidade em alguns pontos - a língua oferece opções não ambíguas -, resta ao leitor a possibilidade de atribuir a tal escolha uma intenção, a saber, uma proximidade/identificação com certas afirmações, ao passo que um distanciamento/oposição em relação a outras. Tais jogos com a linguagem, realizados por um narrador homodiegético, permitem-lhe impregnar o texto com sua personalidade e intenções, desde a escolha temática à estilística, como o exemplo demonstra ${ }^{9}$.

Ainda no caso de diálogos, há uma outra maneira particular de agir: Murau exime-se de apresentar um diálogo na sua forma mais essencial, ou seja, no confronto de falas de dois ou mais personagens. Nas situações apresentadas como diálogos, como é o caso de grande parte do livro, constituído de trechos de conversas com Gambetti, Murau limita-se a apresentar apenas um dos lados da interlocução, transformando o que seria um diálogo num grande monólogo, dando ao leitor sempre uma idéia parcial, nunca apresentando o conjunto, o que permitiria a ele avaliar por si os argumentos dos envolvidos, ao ler como tais se desenvolvem na interação das figuras. Em vários momentos apresenta ataques da mãe e das irmãs contra si, mas nunca na forma de uma verdadeira conversa, apenas de monólogos: ou tem-se só a voz da mãe, ou só a de Murau, mas nunca a interação das duas. Mesmo na segunda parte da obra, quando os personagens encontram-se para o enterro em Wolfsegg, e quando o leitor espera um confronto de Murau com a realidade - pois o que se via até o momento era um observador protegido em Roma - isso não ocorre. Veja-se o exemplo do momento em que Murau e Caecilia caminham juntos rumo ao prédio principal em Wolfsegg (p.292294): Murau comenta sobre a roupa preta da irmã, que lhe fica bem, depois se queixa dos pombos que infestam a propriedade, mas em momento algum obtém resposta - as reações das irmãs, bem como do cunhado, restringem-se quase sempre a desviar o olhar e a calar-se.

Mesmo nos diálogos com Gambetti, espalhados ao longo do livro, o que se vê realmente são monólogos entrecortados por fórmulas obsessivas como "dissera a Gambetti", "falei a Gambetti", etc, mas sem a contrapartida esperada, ou seja, algo como "ele respondeu", "ele retrucou". Qual seria então a função de Gambetti como interlocutor constante?

\section{O interlocutor ideal}

Gambetti é apresentado ao leitor, sob a ótica de Murau, como um italiano rico, culto, um livre pensador, uma pessoa exigente que após longa procura encontra em Murau, por indicação de Spadolini, o mentor ideal. A relação entre os dois é igualmente ideal (p.9), não se diferenciando por vezes, segundo Murau, quem seria o aluno e quem o professor - para o leitor tal equivalência talvez não seja tão evidente, pois a figura do

\footnotetext{
${ }^{9}$ Murau é um narrador que controla de tal forma a narrativa, como foi exemplificado no tocante à reprodução da fala alheia, manipulando os outros personagens quase como bonecos - à semelhança do que diz fazer sua mãe, a qual transformaria Wolfsegg numa casa de bonecas. Até o interlocutor ideal Gambetti parece por vezes mais uma construção de Murau que uma figura autônoma. Se tal não pode ser afirmado, deve-se ressaltar, no entanto, que mesmo este personagem, interlocutor constante, é apresentado sob a perspectiva de Murau, o que inclui, naturalmente, os exageros de quem só pode apresentar o mundo como ele próprio o vê.
} 
italiano aparece quase sempre como ouvinte, o narrador raramente transmite suas reações.

De qualquer forma, Gambetti é descrito como o interlocutor perfeito, capaz de ouvir sem interromper o falante, de modo que as idéias podem desenvolver-se da forma desejada e, ao aceitar Murau como mentor, consolida a autoridade dele. Tal interlocutor, além disso, não oferece uma oposição real ao apresentado: suas reações, quando descritas, são algumas vezes de aparente censura, mas de forma alguma inibem Murau, pelo contrário, apenas o provocam a falar mais. Esta função de Gambetti como estimulador do discurso lembra em muito os interlocutores socráticos, que por suas breves intervenções estimulam o desenvolvimento das idéias expostas por Sócrates e justamente na direção pretendida pelo mestre. Mesmo o modo como Murau ensina Gambetti assemelha-se ao método socrático: por meio de caminhadas e conversas dá-se a aula - cujo conteúdo permanece misterioso ao leitor, uma vez que o relatado por Murau de suas conversas com seu aluno, à exceção da indicação de algumas leituras, resume-se a suas queixas pessoais contra os seus familiares e seu país, ou seja, tudo de caráter muito pessoal e subjetivo. Mesmo quando não fala de fatos relativos ao seu Herkunftskomplex (complexo de origem), a perspectiva subjetiva se mantém. Por exemplo, quando compara a língua alemã e a italiana, taxando a primeira de pesada e opressora, e a segunda de leve e facilitadora da livre expressão, trata-se de afirmações sem qualquer base lingüística-científica, sendo pura opinião.

A escolha de Gambetti como interlocutor é ainda uma forma de se prestigiar, decorrente da descrição positiva do aluno. Como já dito, a apresentação do outro em seu favor é constante, não é função exclusiva de Gambetti, e Murau usa constantemente a descrição de outros personagens para consolidar a imagem que apresenta de si próprio e as censuras de Gambetti consolidam sua auto-imagem de provocador excêntrico, destacado de seu meio, o aluno reconhece o exagero de grande parte das atitudes do mentor e demonstra quase sempre como reação a essas uma risada escancarada - estaria Gambetti, na sua qualidade de interlocutor ideal, sinalizando ao leitor a atitude correta diante da retórica de Murau, ou seja, o riso?

\section{Übertreibungskunst}

Voltando à afirmação quanto ao caráter da língua alemã, este é um exemplo do estilo exagerado que percorre todo o texto e espelha o caráter deste narrador tão presente em cada linha de seu escrito. Tal estilo é comentado explicitamente pelo próprio narrador-personagem em alguns momentos do texto, sob a forma de uma "Übertreibungskunst" (arte do exagero), poética segundo a qual só o exagero torna as coisas claras (p.96), este seria o segredo da obra de arte. Se esse é o ideal de arte do personagem, ao ler Auslöschung o leitor deveria ter em mente tal ressalva, de que tudo é exagero e deformação, o que o alerta para o risível decorrente do exagero, do qual Gambetti parece estar ciente, mas que não destrói o caráter provocativo do livro - outro resultado da poética do exagero.

Übertreibungskunst resulta num estilo repetitivo, no qual certos fatos retornam constantemente e precisam ser retomados inúmeras vezes pelo narrador, estrutura uma linguagem obcecada, condizente com a caracterização de Murau, um personagem também obcecado, atormentado por um passado que sempre retorna e do qual não consegue livrar-se mesmo em Roma. Aliado à poética do exagero está o estilo parcial, 
categórico de Murau, que faz com que os elementos do texto sejam manipulados de forma a produzir um escrito profundamente subjetivo.

A escrita subjetiva foi uma tendência bastante forte da literatura em língua alemã nas últimas décadas do século passado, quando diversos autores experimentaram novas formas de relatar experiências pessoais. Como observa Petersen, o resultado de tal subjetividade é normalmente uma escrita dominada pela melancolia, no entanto o autor caracteriza Auslöschung da seguinte forma: "kein anderer hier einzuordnender Roman (por exemplo, os de Wohmann, Walser, Koeppen, etc) weist auch nur ähnliche Züge auf, so witzig ist kein zweites subjektivisches Erzählwerk" $\left(1991\right.$, p.219) ${ }^{10}$.

Para tal caráter cômico, que ao mesmo tempo em que irrita e angustia o leitor, pode levá-lo espontaneamente ao riso, devido a seu grotesco e suas pretensões de verdades absolutas, contribui em muito o estilo exagerado de Murau - o mesmo que leva Gambetti sempre ao riso.

Exemplos para o estilo cômico podem ser facilmente encontrados por toda a obra. A caracterização do marido de Caecilia, por exemplo, e quase tudo relacionado a esse, sem dúvida incluem-se entre os pontos mais risíveis da obra: o personagem apresentado como um pequeno burguês de Freiburg, não possui sequer um nome, sendo sempre caracterizado por uma profissão curiosa, fabricante de rolhas para garrafas de vinho, o que combina com sua aparente - ao menos sob a ótica com que Murau o apresenta - falta de personalidade. Se tal profissão no texto traduzido é notória por sua extensão, no original alemão, por tratar-se de uma única palavra, o efeito é tanto mais cômico: Weinflaschenstöpselfabrikant, uma palavra enorme que o narrador repete constantemente e atrai a atenção do leitor visualmente, por ocupar quase toda uma linha do texto original, que é apresentado a seguir:

Mutter und Tochter hatten ein Komplot gegründet gegen die Ehe Caecilias mit dem Weinflaschenstöpselfabrikant. Das kann nicht gut gehen, hatte ich vor meiner Abreise nach Wolfsegg zu Gambetti gesagt, meine Schwester Caecilia und ein Weinflaschenstöpselfabrikant aus dem Schwarzwald, das erledigt sich über kurz oder lang, denn alle sind dagegen und Caecilia ist dem Weinflaschenstöpselfabrikant nicht gewachsen, ist er auch ein Dummkopf. (p.133) ${ }^{11}$

Em outra passagem, na qual o exagero cria um efeito entre o risível e o grotesco, e para a qual também é interessante recorrer-se ao texto em alemão, lê-se:

Und dann, hinter diesen, folgt unser nationalsozialistisch-katholisches Volk, dachte ich. Und unsere nationalsozialistisch-katholische Musikkapelle spielt dazu. Und die nationalsozialistischen Böller werden abgeschossen von der Friedhofsrampe und die katholischen Kirchenglocken läuten dazu. Und wenn wir Glück haben, dachte ich, scheint während der ganzen Zeremonie unsere nationalsozialistisch-katholische Sonne, oder es regnet, wenn wir kein Glück haben, der nationalsozialistisch-katholische Regen. (p.444$445)^{12}$

\footnotetext{
10 "nenhum outro romance dessa categoria apresentado aqui possui características sequer semelhantes. Nenhuma outra narrativa subjetiva é tão engraçada."

11 "Mãe e filha armaram um complô contra o casamento de Caecilia e o fabricante de rolhas para garrafas de vinho. Isso não vai acabar bem, dissera a Gambetti antes de minha viagem a Wolfsegg, minha irmã Caecilia e um fabricante de rolhas para garrafas de vinho da Floresta Negra, cedo ou tarde isso vai gorar, pois todos são contra e Caecilia não está à altura do fabricante de rolhas para garrafas de vinho, por estúpido que ele seja." (p.99)

12 "E, então, atrás desses, seguirá nosso povo nacional-socialista e católico, pensei. E com o acompanhamento de nossa banda nacional-socialista e católica. E as salvas nacional-socialistas serão disparadas da rampa do cemitério e os sinos católicos dobrarão em acompanhamento. E se tivermos sorte pensei, nosso sol nacional-socialista e católico brilhará durante toda a cerimônia ou choverá, se não tivermos sorte, a chuva nacional-socialista e católica." (p.326s)
} 
Coerente com sua poética do exagero, mesmo o sol é nacional-socialista e católico na Áustria, na qual todo homem é por natureza nacional-socialista e católico. Se essa é, apesar de todo exagero, apresentada por Murau como a essência austríaca ("O homem austríaco é por natureza um homem nacional-socialista e católico até a medula(...)", p.214 $)^{13}$, como conviver com isso? Seria possível extinguir tal elemento?

\section{Níveis da autobiografia ficcional}

Antes de passar a um estudo das formas de extinção operadas em Auslöschung, resta analisar ainda alguns pontos da construção narrativa em níveis presente no romance. Como já comentado anteriormente, o mesmo é dividido em duas partes, sendo que a ação da primeira parte da obra "Das Telegramm", narrada ao longo de mais de 200 páginas pode ser resumida rapidamente: por volta das duas da tarde Murau recebe o telegrama comunicando a morte dos familiares, faz as malas e parte na mesma noite para Wolfsegg. A segunda parte, "Das Testament", também engloba menos de vinte e quatro horas: Murau chega a Wolfsegg, reencontra irmãs e cunhado e participa do enterro. Embora o tempo utilizado pelo narrador seja sempre um tempo que indique passado, a sensação produzida no leitor é de presente: esse sente como se a ação estivesse sendo narrada à medida que acontece, pois o narrador não antecipa ações, narra tudo sendo fiel às incertezas do momento, sem provocar tensão por revelar detalhes futuros - embora ele já tenha uma visão do conjunto, pois o relato é feito posteriormente, já de volta a Roma e provavelmente um ano após o enterro, levando-se em conta a data de óbito do personagem; mesmo assim Murau procura causar uma impressão de simultaneidade e narra os dois dias da ação principal de forma cronológica.

Poder-se-ia pensar nos eventos acima citados como um primeiro nível da narrativa, implícito durante todo o relato, mas que só vem ao conhecimento do leitor ao seu fim: após o enterro dos pais, Murau em Roma escrevendo seu livro. Este seria realmente o presente do texto marcado pelo tempo verbal (Präsens): "De Roma, onde agora estou de volta (...)" (p.476) ${ }^{14}$, sendo qualquer menção quanto ao momento da escrita omitida durante a mesma. Por ser a realização da autobiografia tratada ao longo do texto como projeto futuro e de difícil realização, a ilusão de presentificação dos eventos narrados se acentua. O segundo nível seria composto pelos dois dias que englobam o recebimento do telegrama e participação no enterro, que compõem o enredo principal narrado. Num terceiro nível estariam, as conversas inumeráveis com Gambetti, as quais tematizam todos os outros eventos anteriores ao enterro (eventos estes que funcionam quase como um quarto nível): a história da propriedade Wolfsegg, de seus proprietários, da família Murau como um todo, da Áustria, etc., contados simultaneamente à ação principal, mas não de forma cronológica, pois o relato desses eventos é motivado por associações de idéias, por lembranças do narrador.

Parece bastante apropriada a comparação da estrutura narrativa construída em Auslöschung com a do romance autobiográfico Kindheitsmuster de Christa Wolf. Em Kindheitsmuster vê-se uma narrativa na qual diferentes níveis correspondem a

\footnotetext{
13 "Der österreichische Mensch ist durch und durch ein nationalsozialistisch-katholischer von Natur aus (...)" (p.292s)

14 "Von Rom aus, wo ich jetzt wieder bin (...)" (p.651)
} 
diferentes momentos temporais, como no caso do livro de Bernhard, mas com a diferença de que tais níveis são indicados pelo uso de diferentes pronomes pessoais, de modo que o "diálogo consigo próprio" fica muito mais evidente: num primeiro nível terse-ia a infância da narradora, a qual se refere a si própria na infância pelo uso da terceira pessoa do singular, enquanto num segundo nível, o qual mostra dois dias de viagem da narradora de volta à cidade de sua infância, ela dirige-se a si mesma na segunda pessoa do singular - tal ocorre em Auslöschung também, mas não de forma tão sistemática. Num terceiro nível da narrativa estariam os atos de reflexão da narradora durante a escrita, e haveria ainda um quarto nível constituído por elementos da comunicação real do presente da escrita (trechos de notícias de jornal, por exemplo).

Em Wolf os níveis são paralelos, como em Bernhard, no entanto o autor austríaco não utiliza um recurso estilístico tão forte para marcá-los, como Wolf faz com o uso dos pronomes - em Bernhard, poder-se-ia argumentar, o relato do passado anterior ao dia do recebimento do telegrama (níveis 3 e 4 nessa análise) é narrado na forma de citação de conversa com o aluno Gambetti, mas tal não é uma regra absoluta do texto, embora seja o caso comum.

\section{ANTIAUTOBIOGRAFIA COMO TENTATIVA DE EXTINÇÃO}

\section{Escrever para extinguir}

Acima se apresentou uma comparação entre Auslöschung e Kindheitsmuster a fim de mostrar as semelhanças na construção dos romances em diferentes níveis narrativos e dos personagens que trabalham a reconstrução da experiência pessoal. Ambos os relatos apresentam personagens que se voltam em direção ao passado e analisam suas experiências até o momento atual, no entanto é preciso ressaltar que a intenção que está na base de tal atitude é diferente nos dois casos: enquanto a personagem de Kindheitsmuster empreende uma busca pela reconstrução de sua identidade, para Murau os caminhos que o transformaram no que é são bem claros e precisam ser destruídos, de forma que a escrita autobiográfica é encarada, paradoxalmente, como se poderia $\operatorname{argumentar}^{15}$, como forma de extinção por meio da construção do relato escrito: "Todos nós carregamos uma Wolfsegg conosco e temos vontade de extingui-la para nossa salvação, ao querermos pô-la por escrito, queremos aniquilá-la, extingui-la." (p.148s) ${ }^{16}$.

Murau afirma ainda que seu relato existe apenas para extinguir tudo que nele estiver contido: sua família, época, pátria e conseqüentemente a si mesmo, o que parece necessário, por estar impregnado todo o tempo por Wolfsegg e seu complexo de origem (p.147).

\footnotetext{
${ }^{15}$ Schlichtmann lembra o fato de que se deve diferenciar o processo de extinção, pretendida por Murau, em duas perspectivas diferentes: a do leitor e a do autor. Para o leitor Auslöschung, enquanto texto escrito, constrói-se sempre e de novo por meio da leitura, já para o autor-personagem escrever sobre seu complexo é uma forma de liberta-se dele, de forma semelhante ao que ocorreria na psicanálise: tornar explícito o elemento recalcado, a fim de superá-lo. (1996, 136).

16 "Wir tragen alle ein Wolfsegg mit uns herum und haben den Willen, es auszulöschen zu unserer Errettung, es, indem wir es aufschreiben wollen, vernichten wollen, auslöschen.” (p.199)
} 
No entanto, uma extinção simbólica aparentemente não é possível: a tentativa de fugir desse complexo na Itália falha. Como vemos na primeira parte do livro, passada em Roma, Wolfsegg é constantemente relembrada e torna-se matéria contínua de seus diálogos e pensamentos - a distância espacial não é suficiente para afastá-lo de suas origens. Além disso, como vemos por meio de algumas de suas afirmações, sempre categóricas e absolutas, o austríaco seria essencialmente nacional-socialista e católico, não importa o que faça. A afirmação é exagerada e subjetiva, dentro do estilo de toda obra, mas a conseqüência é nefasta: se esta é fatalmente a essência de todo austríaco, como se subtrair a tal? Não sendo suficiente o exílio em Roma, ou uma extinção simbólica, encadeiam-se várias extinções concretas: já na primeira frase do livro a morte dos pais e irmão inicia a extinção da família, que é completada, na última frase, pela morte do próprio Murau e a doação da propriedade à comunidade judaica - o que de certa forma aniquila as irmãs, agora totalmente sujeitas ao marido de Caecilia, fadadas a acompanhá-lo a Freiburg.

Da morte de Franz-Josef o leitor é informado no final do livro por um narrador aparentemente extradiegético: "escreve Murau (nascido em 1934 em Wolfsegg, morto em 1983 em Roma)" (476) ${ }^{17}$. Ao ler tal frase ao fim do romance, é muito provável que o leitor retorne ao seu começo e relembre a moldura na qual ele está inserido, introduzida pela forma "escreve Franz-Josef Murau" (p.7), já nas primeiras linhas do texto. Tal moldura é facilmente esquecida por estar restrita somente a essas duas pequenas frases, desaparecendo ao longo da obra.

Murau, por todo seu relato, admite que só é quem é por causa de Wolfsegg, sem a qual nada seria, de modo que a extinção de Wolfsegg implica necessariamente sua própria extinção, como escreve Korte em sua análise de Auslöschung: "Murau existiert nur durch und wegen und gegen Wolfsegg" $(1991, \mathrm{p} .80)^{18}$.

O texto apresenta então duas necessidades contraditórias: de um lado a tríade $\mathrm{A}=\mathrm{N}=\mathrm{P}$, equação de Genette e condição de uma autobiografia (ainda que fictícia), que pelo fato de tratar-se de um relato homodiegético assegura uma unidade forte entre conteúdo e forma, garantindo a subjetividade pretendida pelo relato, de outro a morte do protagonista é a conseqüência necessária do projeto Auslöschung. Já na epígrafe escolhida, uma citação extraída de Montaigne ${ }^{19}$, que ecoa por todo o texto, vê-se a menção à morte que está por toda parte e condiz com as várias referências de Murau de que lhe restaria pouco tempo de vida (cf., por exemplo, p.147). O leitor de Bernhard sabe que a morte, loucura ou suicídio são finais comuns a vários personagens do autor. No caso de Murau, não há informações quanto às causas de sua morte, sendo doença e suicídios possibilidades plausíveis: o personagem já se apresentara anteriormente como doente, e por sua perturbação, o suicídio também seria uma saída verossímil.

\footnotetext{
17 “schreibt Murau (geboren 1934 in Wolfsegg, gestorben 1983 in Rom)” (p.651)

18 "Murau existe tão somente por meio de Wolfsegg, por causa de Wolfsegg e contra Wolfsegg."

${ }^{19}$ Montaigne igualmente abre seus Ensaios com uma referência à morte: em uma advertência ao leitor escreve, por saber estar próximo de seu fim, um livro, cujo intuito é falar de si, "eu mesmo sou a matéria deste livro" (1972, p.11), para deixar aos seus leitores um pouco de sua personalidade e idéias. Além da idéia da morte contida na epígrafe, outro ponto de contato entre o escrito de Montaigne e a autobiografia de Murau é o método: tratar de variados assuntos como forma de falar de si mesmo. O filósofo afirma: "não viso explicar ou elucidar as coisas que comento, mas tão somente mostrar-me como sou" (ibid., p.196), o que, como se tenta mostrar, é um dos objetivos (não declarados) de Murau, ou seja, descrever Wolfsegg para descrever a si mesmo.
} 


\section{A morte do narrador}

O problema da apresentação da morte do narrador num relato homodiegético apresenta diversas soluções, dentre as quais a mais comum seria a quebra da perspectiva subjetiva do relato e o recurso à apresentação externa da morte, por um observador ou, no caso de um relato que se supõe escrito (cartas, diário, livro fictício, etc), pela fala de um editor a informar o leitor do desfecho da história, como no caso de Os sofrimentos do jovem Werther, no qual um editor fictício, presente ao longo de todo o texto, faz a ponte entre o leitor e as cartas do personagem. O editor de Werther apresenta-se como uma personagem do universo ficcional dessa obra, um interessado no caso do jovem, disposto a reunir todas as informações possíveis sobre o caso, e que informa o leitor do provável suicídio do personagem, já insinuado em seu último escrito. Outra possibilidade, que apresenta mais dificuldades para o escritor, seria a adotada por Schnitzler em Fräulein Else: o leitor acompanha o fluxo de consciência da personagem e é posto frente à interrupção do mesmo, sinalizada pela dificuldade de formular frases - decorrente de uma dose excessiva de um remédio tomado pela moça -, e pelo corte abrupto de suas palavras, abandonando o leitor com a suposição de que tal silêncio deve-se à morte da narradora-protagonista. Neste caso, o leitor supõe a morte, mas há sempre certa dose de incerteza.

No caso de Auslöschung, a possibilidade de apresentar a morte do narrador na primeira pessoa é quase nula, pois se trata de um texto escrito. Contudo, o editor anônimo que nos comunica o falecimento de Murau, o faz de forma muito sucinta, calando-se sobre as causas da morte do personagem. Falar mesmo em editor do texto é algo que esse não autoriza: aceitar que as duas inserções no texto de Murau foram feitas por um editor, é supor que seriam fruto de um personagem do universo ficcional apresentado e não há qualquer indício no texto que autorize tal argumentação. Assim, pretender que tais inserções sejam feitas por Gambetti ou outro personagem, como querem alguns críticos como Gößling ou Marquardt (cf. SCHLICHTMANN, 1996, p.31), é problemático, pois não há qualquer indício concreto para embasar tais conclusões, pelo contrário, o tempo presente utilizado ("schreibt") só causa estranhamento, supondo tratar-se de uma figura do universo ficcional ao qual pertence Murau. A última frase do suposto editor é também curiosa, por novamente usar o presente e em tom quase oficial-burocrático anunciar as datas de nascimento e óbito do narrador-personagem.

Se tudo indica não se tratar de um editor fíctício - o que implicaria ser um personagem -, resta considerá-lo um narrador autorial, extradiegético, que no início do livro introduz uma citação (o escrito de Murau) e, após mais de 600 páginas, reaparece para fechá-la. Retomando a já comentada construção em níveis, pode-se afirmar agora que o leitor se defronta com uma construção narrativa labiríntica, semelhante à imagem de uma porta que ao ser aberta leva a uma outra e assim sucessivamente, uma vez que se tem um narrador autorial a comunicar em discurso direto o que Murau escreveu em Roma. Ele, em seu escrito, apresenta o que se passou em dois dias ocorridos há cerca de um ano, o que por sua vez inclui uma série de citações de seus próprios discursos e pensamentos ocorridos durante esses dois dias, incluindo também a lembrança de fatos anteriores a esses dias - lembranças geralmente apresentadas não diretamente, mas na forma de citação de um diálogo anterior consigo próprio ou com Gambetti. 
Em Nouveau Discours du Récit (1983, p.55-57), Genette apresenta um esquema ilustrando o encadeamento de inúmeros níveis narrativos de um texto, o qual é tomado aqui de empréstimo por ser elucidativo no caso do texto comentado:

\section{A}

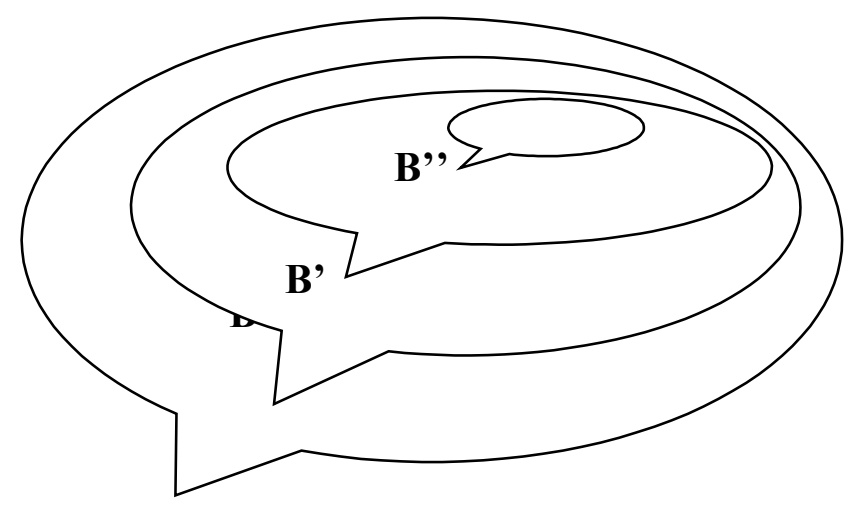

$\mathrm{Na}$ ilustração, $A$ designa o narrador extradiegético anônimo, ao passo que $B$ seria Murau ao escrever em Roma, presença implícita ao longo do texto - embora o leitor só a reconheça ao final do mesmo. $B$ ' é o Murau dos dois dias narrados ao longo das mais de 600 páginas e $B$ " refere-se a Murau de um momento temporal desconhecido, em suas constantes conversas com Gambetti, nas quais narra e comenta os mais diversos fatos, e que é relembrado e citado pelo Murau da ação principal ( $\left.B^{\prime}\right)$. Voltando à comparação entre o romance em questão e Kindheitsmuster, a instância narrativa A seria estranha à segunda, por tratar-se de uma voz estranha ao relato.

De qualquer modo, se não é possível decidir quanto à identidade do narrador $A$ ilustrado no esquema, deve restar a possibilidade de atribuir-lhe uma função, como foi comentado anteriormente, a saber, comunicar a morte do narrador, exigida pelo romance.

No entanto, há outras questões concernentes à estrutura do texto que ficam em aberto: quem teria escolhido a epígrafe de Montaigne para o escrito, Murau ou o narrador $A$ ? Sabemos que Murau cita Montaigne como um dos escritores integrantes de seu cânone particular e a epígrafe condiz com a morte do protagonista, tematizada por ele como próxima. Decidir tal fato viria da resposta a uma outra questão: se Auslöschung é o título do escrito de Murau, o que dizer do subtítulo Ein Zerfall, que não é mencionado no corpo do texto? Pensando como Schlichtmann (ibid., p.33), o subtítulo seria o que distingue o relato de Bernhard do de Murau, delimitando o início da ficção. Se considerarmos ambos como pertencentes ao escrito de Murau, o livro ganha uma qualidade especial: o mundo ficcional desta narrativa inicia-se já antes do relato propriamente dito, ou seja, já no título, o qual normalmente constitui um nível à parte do universo ficcional apresentado.

Ainda assim, deve-se pensar em que o subtítulo altera o título. Auslöschung ou extinção são palavras indicadoras de um processo com agente (auslöschen: verbo transitivo), enquanto Zerfall, na tradução brasileira "derrocada", sinaliza um processo sem agente (zerfallen: verbo intransitivo). $\mathrm{O}$ que pretenderia o autor: é preciso assumir a tarefa e extinguir tudo? Ou extinção é o resultado inevitável do processo de derrocada que está em curso? 
Bernhard, em seu estilo jocoso, comenta o título numa entrevista: ““Auslöschung', ein guter Titel, ausgezeichnet: 'Auslöschung. Ein Zerfall'. Einer löscht alles aus, und drum herum zerfällt sowieso alles, also ist es eigentlich ein Blödsinn, daß er es auslöscht, weil eh alles zerfällt" (FLEISCHMANN, 1991, p.253) ${ }^{20}$. Com tal comentário irônico Bernhard exime-se de qualquer resposta e acaba por também se questionar, como seus próprios personagens costumam fazer.

\section{CONSIDERAÇÕES FINAIS}

Após a publicação dos cinco volumes autobiográficos de Thomas Bernhard, algumas tendências desse gênero se consolidaram na prosa do autor como, por exemplo, o uso da narração em primeira pessoa. No entanto Auslöschung é o único romance que simula claramente o gênero tematizado no pacto que Murau estabelece com seu leitor: ao longo do livro o personagem apresenta a intenção de empreender uma autobiografia, e apresenta o porquê de sua necessidade (extinguir o que nela for escrito), os temas que devem ser trabalhados (Wolfsegg, família, o caso do casal Schermaier, etc). O título ideal é debatido, o mentor da idéia, tio Georg, é apresentado. Se Auslöschung é tematizada como um projeto futuro, ao fim do romance o leitor surpreende-se ao ser informado de que o livro em mãos é na verdade a própria Auslöschung - tal opção é coerente com a perspectivação dada por Murau, o qual optou por narrar os eventos conservando uma ilusão de presente a partir dos dias que compõem a narrativa principal.

A perspectiva de Murau não fica patente só na escolha do momento temporal privilegiado, mas está implícita em todas as escolhas do texto, algumas das quais foram tematizadas na primeira parte deste trabalho. A tensão entre o personagem e seu complexo de origem, temática decorrente da escolha do gênero autobiográfico, parece ser o principal elemento a dominar a narrativa, uma obsessão do personagem com a qual o leitor é confrontado a cada linha do texto, e que determina o modo como o romance se configura, desde a escolha de episódios que tematizam o conflito - de preferência mostrando como o narrador-protagonista se destaca de seu meio, e ao mesmo tempo indicando como tais origens são vulgares. Ao dar voz aos outros personagens o faz de modo a obter o controle da matéria citada em favor de seu próprio discurso, de forma a apresentar ao leitor sempre uma visão parcial, além de apresentar os fatos sob o filtro de sua poética do exagero, a qual determina as principais características do estilo de Murau, a saber, a repetição constante, o exagero das afirmações, sempre categóricas, subjetivas, o que produz muitas vezes o efeito cômico.

Esse cômico, contudo, freqüentemente contém simultaneamente um elemento perturbador, provocador, cujo efeito beira o trágico: talvez para o leitor estrangeiro não seja tão claro, mas para um concidadão de Bernhard ver um povo e suas instituições, bem como os menores detalhes de sua cultura, serem criticados de forma tão aguda provavelmente constitua uma experiência trágica - se não trágica, no mínimo bem incômoda, como atestam os processos e ameaças com as quais o autor teve de conviver ao longo de sua vida. É verdade também que muitas passagens do texto não possuem qualquer argumentação objetiva, como é o caso já citado da comparação entre língua

20 “'Extinção', um bom título, excelente. 'Extinção. Uma Derrocada'. Alguém extingue tudo e de qualquer modo a coisa toda já está ruindo. Então é realmente uma idiotice que se queira extinguir, se tudo já está ruindo mesmo." 
alemã e italiana, mas por vezes a argumentação é sóbria e cruel, como no retrato que faz de Wolfsegg e dos seus habitantes durante o período nazista, ou no exemplo dramático do camponês Schermaier, delatado pelos vizinhos por ouvir uma transmissão suíça.

$\mathrm{Na}$ segunda parte da análise discutiu-se o projeto extinção não em seu valor catártico de trabalhar o passado a fim de libertar-se desse, quase como a psicanalista trata experiências traumáticas, ou de trabalhar possíveis contradições entre extinguir (destruir) e escrever (construir). Em vez disso procurou-se apreender como justificar a narração encaixada numa moldura constituída por um narrador anônimo, ligando-a ao projeto extinção, que inclui a necessidade de extinguir o próprio autor do texto, uma vez que sem Wolfsegg ele não seria quem é ("Eu não seria quem eu sou se Wolfsegg fosse outra", p. 79), de modo que destruir Wolfsegg, o que faz de forma simbólica, é se autodestruir, implicando assim em sua morte - a extinção simbólica de Wolfsegg parece ser insuficiente.

Não se pode deixar de notar o caráter trágico de tal situação: a consciência de uma origem repudiada que o persegue a todo instante e da qual tenta libertar-se a todo custo, sem sucesso, pois tal liberdade implica destruição de tudo que ele é, enquanto resultado dessa mesma e odiada origem. Assim sendo, a morte do personagem é uma sombra a acompanhá-lo durante todo o relato e que se apresenta como único fim possível.

Só um narrador homodiegético que se coloca no centro do narrado, como é o caso da autobiografia, teria autoridade para realizar tal construção tão subjetiva e coerente com a perspectiva escolhida, sendo bem sucedido em apresentar a tragédia, que é uma perfeita e pérfida comédia, na qual o personagem vive.

\section{REFERÊNCIAS}

BERNHARD, Thomas. Auslöschung: Ein Zerfall. Frankfurt a. Main: Suhrkamp, 1996. Extinção: Uma Derrocada. Trad. José Marcos Mariani de Macedo. São Paulo: Companhia das Letras, 2000.

Duden v. 4 - Die Grammatik. Mannheim: Dudenverlag, 2005.

FLEISCHMANN, Christa. Thomas Bernhard: Eine Begegnung. Wien: Österreichische Staatsdruckerei, 1991.

GENETTE, Gérard. Fiction et Diction. Paris: Éditions du Seuil, 1991. , Nouveau Discours du Récit. Paris: Éditions du Seuil, 1983.

KORTE, Hermann. Dramaturgie der "Übertreibungskunst"- Thomas Bernhards Roman Auslöschung. Ein Zerfall. In: ARNOLD, Heinz Ludwig (org.). Text + Kritik-

Zeitschrift für Literatur, n. 43. Munique: Edition text+kritik, 1991.

LEJEUNE, Philippe. Der autobiographische Pakt. In : NIGGL, Günter (org.). Die

Autobiographie: zu Form und Geschichte einer literarischen Gattung. Darmstadt: Wissenschaftliche Buchgesellschaft, 1989.

MONTAIGNE, Michel de. Ensaios. Tradução Sérgio Milliet. São Paulo: Abril Cultural, 1972.

PETERSEN, Jürgen H. Der deutsche Roman der Moderne: Grundlegung - Typologie Entwicklung. Stuttgart: Metzler, 1991.p. 211-224.

SCHLICHTMANN, Silke. Das Erzählprinzip 'Auslöschung': Zum Umgang mit Geschichte in Thomas Bernhards Roman Auslöschung. Ein Zerfall. Frankfurt a. M: Peter Lang, 1996. 
STANZEL, Franz. K. Typische Formen des Romans. Göttingen: Vandenroeck e Ruprecht, 1965.

WOLF, Christa. Kindheitsmuster. Munique: Luchterhand, 2000. 